\title{
Agencias que importan. Un conjunto fotográfico (im)pertinente
}

Investigadora Instituto Interdisciplinario de Estudios de Género-Facultad de Filosofía y Letras-Universidad a los derechos humanos en el pasado reciente argentino: memorias de mujeres". Directora Equipo UBA en SPEME (RISE H2O20 MSCA-U.E.). Publico sensibilidades. Mujeres $y$ tensiones de génevas Argentina siglo XX" en Yoel, Gerardo (comp.) Género y Silencios, Los Polvorines, Ediciones Universidad Nacional Gral. Sarmiento. 2019. Dirección: UBA Viamonte 430, C1053, CABA, Buenos Aires, Argentina. ORCID: http://orcid.org/0000-0003-3920-9795.

E-mail: lizelt@gmail.com

Recebido em: 04/05/2019

Aprovado em: 05/07/2019.

Dirección:

UBA Viamonte 430, C1053, CABA, Buenos Aires, Argentina.

\section{Agencies that matter. A set of (im)pertinent photographies Agências que importam. Um conjunto fotográfico (im)pertinente}

Hurí Elisabeth Tornay ${ }^{1}$

Universidad de Buenos Aires, Facultad de Filosofía y Letras, Instituto Interdisciplinario de Estudios de Género (IIEGE), Buenos Aires, Argentina.

\section{RESUMEN}

Un conjunto de fotografías tomadas y publicadas por dos diarios de la ciudad de Mendoza (Argentina), en el mes de febrero de 1976 y las entrevistas realizadas a algunos de los fotografiados y a periodistas de los diarios en cuestión permiten indagar en torno a los regímenes de visibilidad y paralelamente focalizar la dificultad de considerar a las víctimas, en tanto tales, junto al valor de sus agencias.

PALABRAS CLAVE: Régimen de visibilidad; Víctimas; Agencia.

\section{ABSTRACT}

A set of photographs taken and published by two newspapers in the city of Mendoza (Argentina), in the month of February 1976 and interviews with some of the photographers and journalists of the newspapers in question allow us to inquire about the regimes of visibility and in parallel to focus the difficulty of considering the victims, as such, together with the value of their agencies.

KEYWORDS: Regimes of visibility; Victims; Agencies.

\section{RESUMO}

Um conjunto de fotografias tiradas e publicadas por dois jornais na cidade de Mendoza (Argentina), no mês de fevereiro de 1976 e entrevistas com alguns dos fotógrafos e jornalistas dos jornais em questão nos permitem indagar sobre os regimes de visibilidade e, paralelamente, focalizar a dificuldade de considerar as vítimas, como tal, juntamente com o valor de suas agências.

PALAVRAS-CHAVE: Regimes de visibilidade; Vítimas; Agências. 
"En un contexto mundial donde se ven eclipsadas las utopías las investigaciones en torno a las construcciones de la memoria corren el riesgo de que el recuerdo de las víctimas no pueda coexistir con el de sus combates, sus conquistas y sus derrotas". (TRAVERSO, 2012: 296)

En este artículo intentaremos indagar un conjunto de fotografías, su circulación y recepción teniendo en cuenta esta advertencia a modo de precaución metodológica.

En 2009 Huyssen (2009) planteaba "Sospecho que es demasiado pronto para afirmar con seguridad que el terror argentino permanecerá carente de imágenes". (HUYSSEN, 2009, p. 20). Si en ese momento era posible hablar de la carencia de imágenes en 2019 podemos afirmar que en los diez años transcurridos desde entonces han circulado imágenes que dan cuenta del terrorismo de Estado impuesto por la última dictadura militar argentina.

Al respecto "(...) no faltan imágenes sino ojos que las vean (...)” (GARCÍA Y LONGONI, 2013, p.28). Algunas fotografías deslizadas por los intersticios del horror en los momentos previos al golpe militar de 1976 en Argentina cuando las Fuerzas Armadas ya estaban implementando la metodología de la desaparición forzosa de personas; algunas otras sacadas furtivamente por un ex detenido desaparecido de la ESMA ${ }^{2}$; y luego aquellas obtenidas como consecuencia de la presión social de los Archivos del Estado dictatorial una vez que retornó la democracia ${ }^{3}$, sustentan la anterior afirmación. La circulación pública de estas imágenes interpela la invisibilidad de las mismas.

¿Cuál es la dificultad que las invisibiliza como evidencia del horror? ¿Cuál es el régimen de representación visual que sustenta esa invisibilidad? ¿Cómo interpelar los presupuestos de una racionalidad 'transparente' como la que está en la base de la idea misma de una representación (visual) directa?

Avanzaremos en torno a esta problemática tomando en cuenta paralelamente la precaución de no solo focalizar en las víctimas como tales sino también en las agencias.

Algunas de las cuales fueron publicadas (BRODSKY, 2005).

Fotos que tomó la Dirección de Inteligencia de la Policía de la Provincia de Buenos Aires, exhibidas en una muestra realizada por la Comisión Provincial de la Memoria de La Plata en 2008, las imágenes de ciudadanos argentinos detenidos en Paraguay o paraguayos detenidos en Argentina incluidas en el Archivo del
Tomaremos entonces un conjunto de fotografías publicadas dentro de un artículo en los diarios El Andino y Los Andes (ciudad de Mendoza, Argentina) los días 22 y 23 de febrero de 1976 respectivamente. ¿Cómo se deslizaron? ¿Por qué intersticios? ¿En qué medida lo hizo posible el accionar burocrático todavía no suficientemente organizado para llevar adelante la metodología de la desaparición forzada de personas? ¿0 tal vez, algunas subjetividades irreverentes? Asimismo, en el momento de enunciación de los años de su publicación ¿qué relato sustentó una sensibilidad incapaz de visibilizar las marcas del horror en esas imágenes?

Con estos interrogantes se considerarán los aportes de los relatos de algunos de los fotografiados, entonces secuestrados en el Centro Clandestino de Detención que funcionaba debajo del Palacio Policial Departamento 2 (D2) de la ciudad de Mendoza, en diálogo con las narraciones de quien fuera en ese momento el subdirector de ambos diarios en ejercicio de la dirección, Antonio Di Benedetto, y de otros periodistas de esos medios.

Esta investigación tomó como supuestos iniciales de análisis en primer lugar el concepto de representación que plantea Didi Huberman (2015) retomando a Benjamín, al considerar que la representación (en este caso visual), en tanto tal, implica intrínsicamnte una sustracción.

Asimismo, el lenguaje verbal y las imágenes se complementan, se completan, se interpelan, pero no pueden traducirse a modo de espejo en tanto responden a lógicas diferentes, el primero ligado al mundo de los conceptos, las otras sustentadas en el mundo sensible. En este sentido palabras e imágenes se enriquecen mutuamente. (MARIN, 1993)

Paralelamente, consideramos la diversidad de temporalidades que conforman tanto las narrativas verbales como las sensibilidades en la que se sustenta el mundo de las imágenes. Los cambios en los escenarios políticos, la aparición de nuevos actores sociales y las variaciones en las sensibilidades inevitablemente producen transformaciones en los sentidos del pasado (JELIN, 2002). Esto es así en tanto los significados de los acontecimientos del pasado no se establecen de una vez para siempre, sino que se constituyen como resultado de complejas interacciones. Más aún cuando se incorpora la dimensión de lo traumático. Se trata de situaciones cuya intensidad genera en el sujeto trastornos diversos. Kaufman (1998) señala al respecto que: "(...) en el momento del hecho, por la intensidad y el impacto 
sorpresivo, algo se desprende del mundo simbólico, queda sin representación (...). Será difícil o imposible hablar de lo padecido" (KAUFMAN, 1998, p.12).

Se agregan entonces a la compleja trama de las temporalidades las dificultades propias de la elaboración de situaciones traumáticas.

En función de complementar y/o contrastar relatos y fotografías que, en tanto construcciones, involucran diferentes actores, lógicas y contextos socioculturales, será necesario analizar el espesor histórico de dichas construcciones considerando las diferentes temporalidades, es decir, el momento político e histórico de producción del artículo en cuestión que responde a un tiempo de enunciación, las diversas temporalidades de su circulación, y el tiempo de nuestra mirada y recepción.

\section{Recuerdos y temporalidades}

Una de nuestras entrevistadas, Silvia Ontivero, era delegada de la Asociación de Trabajadores del Estado y militante de la Juventud de Trabajadores Peronistas ${ }^{4}$. Entrevistada en 2012 así recordaba esa experiencia:

(...) Yo pertenecía a la Asociación de Trabajadores del Estado,(...) estaba en la comisión directiva por la lista de oposición a la burocracia.(...) En noviembre del '75 las Fuerzas Armadas toman el poder detrás del trono, estaba Isabel [viuda del Gral. Perón y vice presidenta en ejercicio de la presidencia de la Nación], y finalmente en febrero avanzan sobre los sindicatos (...) sobre todas las listas que en el país estaban oponiéndose a esta burocracia, que luego fue, además, amiga del golpe [de Estado producido en Argentina el 24 de marzo de 1976].

Corrían los primeros días de febrero, se produce un hecho de sangre, (...) de un policía en la calle Godoy Cruz [ciudad de Mendoza], donde no tenemos nada que ver. Entonces ponen preso a todo el cuerpo de delegados prácticamente entero, nos van a buscar a las casas. (...) nos llevan al Palacio Policial de Mendoza, el D2.

4 Silvia Ontivero fue secuestrada en el mes de febrero de 1976, durante el gobierno constitucional de Isabel Perón, un mes antes del golpe militar que instauró la última dictadura argentina (24/03/76). Permaneció 18 días detenida desaparecida en el D2de Mendoza. Luego fue legalizada como presa política y trasladada al penal de Villa Devoto (provincia de Buenos Aires). Salió en libertad en diciembre de 1983.
A mí me secuestraron y lo secuestraron a mi hijo junto conmigo. (...) Estamos ahí dieciocho días (...) A las mujeres nos empezaron a manosear desde el primer día. (...) somos mujeres, somos putas si militamos, (...) muy rápidamente (...) empezaron las violaciones. Yo recuerdo haber sido violada por, por lo menos, diez o doce hombres (...) lo que vivimos esos dieciocho días, casi nada de comida baño un par de veces, violaciones constantes, sentir cerca nuestro que a los compañeros también estaban golpeándolos (...) yo estaba muy desfigurada la cara, me habían roto la nariz (...() [Los médicos de la Cruz Roja, en 1979] me operaron en [la cárcel de] Devoto, me devolvieron la respiración (....)" 5

Figura 1- Fragmento del artículo “Sobre la detención de personas extremistas informó la Policía"

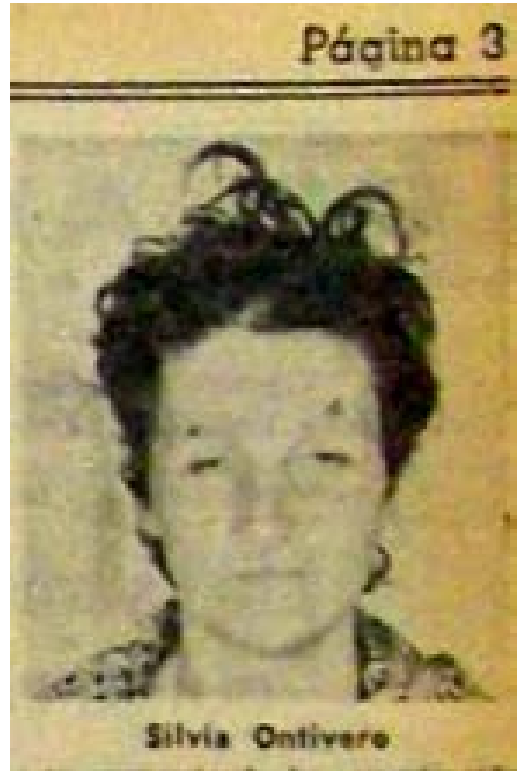

Fuente: Diario Los Andes (Mendoza, 23-02-76, pág. 3)

Entrevista realizada por Lizel Tornay y Fernando Álvarez en Viña del Mar, Chile, febrero de 2012. 
Esta mujer, nuestra entrevistada, tal como aparece en esta imagen, estuvo allí, es el indicio que muestra la fotografía, lo que Roland Barthes considera como "eso fue" (BARTHES, 1982) y/o la "traza de un real" según Phillipe Dubois (2015, p.169). En este punto la imagen fotográfica se transforma en objeto de investigación en sí mismo.

Fernando Rule Castro, otro de nuestros entrevistados, integrante del mismo grupo de secuestrados y entonces pareja de la entrevistada citada, agrega algunos detalles al relato anterior:

Figura 2 - Fragmento del artículo "Sobre la detención de personas extremistas informó la Policía”

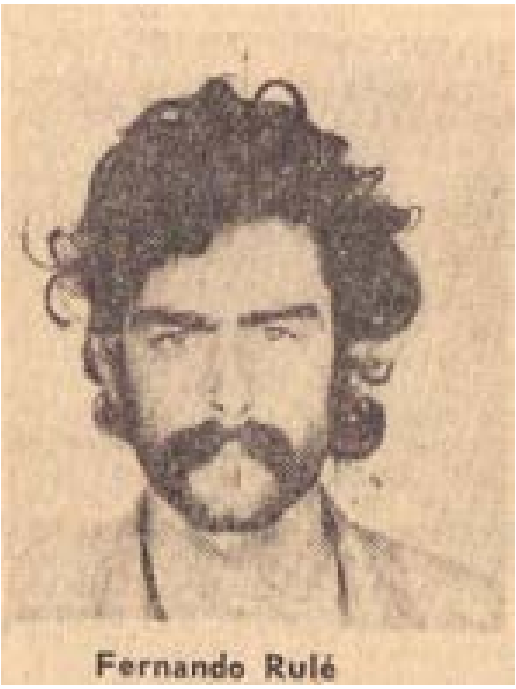

Fuente: Diario Los Andes (Mendoza, 23-02-76, pág. 3)

ese fue un secuestro ilegal, al mando de un civil (...) integrante de un grupo de elite que se llamaba 'centro de instrucción contra subversivo'. (...)

No más ver la foto que sale en el diario. (...) Yo creo que sacada deliberadamente. Nos sacan la venda, nos sacan la foto y nos vuelven a vendar.
(...) Bueno esas fotos que impresionan de forma que la clase media diga, 'mirá qué cara de asesinos que tienen'. (...) ${ }^{6}$

Estas fotografías integraban el relato de un artículo publicado en los diarios El Andino y Los Andes, los días 22 y 23 de febrero de 1976 respectivamente.

Figura 3 - Fragmento del artículo "Sobre la detención de personas extremistas informó la Policía"

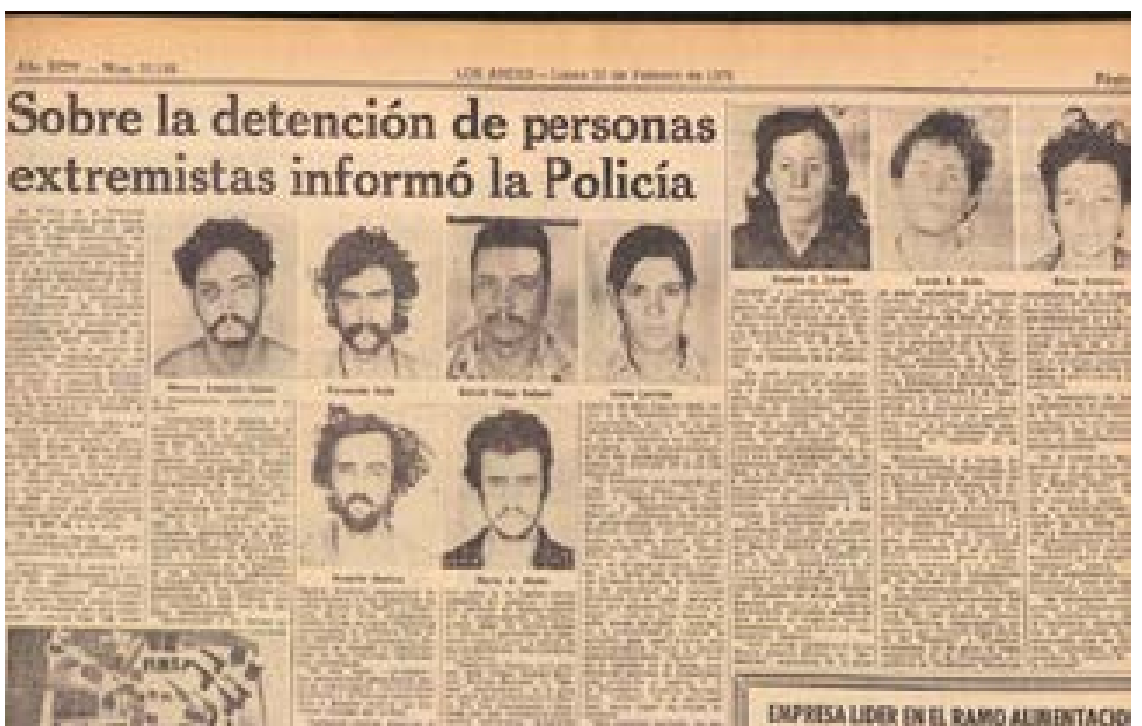

Fuente: Diario Los Andes, 23-02-76, p. 3.

Empecemos por los tiempos históricos de producción y enunciación de estas fotografías. Cuando se publicaron, en febrero de 1976, transcurría el gobierno constitucional de María Estela Martínez de Perón. Desde el mes de noviembre de 1975 los militares habían tomado el control operacional de las fuerzas de seguridad del país por imperio de la Ley de Seguridad Nacional y debido a los decretos presidenciales de aniquilamiento de la "subversión". Hacia fines de ese año eran frecuentes las detenciones y desapariciones forzosas de militantes de organizaciones de izquierda en todo el país. Para

6 Entrevista realizada por Lizel Tornay y Fernando Álvarez, en la ciudad de Mendoza, febrero de 2012. 
la aplicación de esta metodología se empezaron a implementar los primeros centros clandestinos de detención.

Ese clima político fue impuesto claramente por los integrantes de las Fuerzas Armadas en las redacciones de los diarios. Así lo describe el periodista del diario Los Andes, Rafael Morán:

A principios de noviembre de 1975 (...) dos altos oficiales de la Aeronáutica llegaron a Los Andes (...) Recuerdo perfectamente la frase de esos individuos: 'se terminó la joda, desde mañana no se podrá publicar nada que afecte a las fuerzas armadas'. (...) Pero la gente llegaba todos los días a Los Andes para denunciar que hijos, padres, hermanos habían sido detenidos y estaban desaparecidos. (...) Hasta que en una ocasión una mujer vino a llorar por su hijo de la Juventud Peronista al que se habían llevado y no sabía dónde estaba. (...) Ese día Di Benedetto me autorizó a publicar una pequeña crónica. (...) Progresivamente fuimos publicando otros hechos, (...) lo cual nos llevó a la cárcel apenas alumbró el golpe militar (GELÓS, 2011, p. 49-50).

En una entrevista realizada en 1983, cuando había finalizado la dictadura militar, Antonio Di Benedetto decía: "Nunca he hecho política de ninguna especie (...) De ahí a adherir a grupos de fuerza hay un trecho".7

Estos periodistas rompieron, de este modo, la censura impuesta por las fuerzas de seguridad.

Curiosamente cada una de las fotografías aparecidas en el artículo los días 22 y 23 de febrero de 1976 tenía como epígrafe el nombre y apellido de las personas secuestradas, cuyo paradero se desconocía. Se trataba entonces de una información decisiva y poco habitual en esos momentos. Tal vez esas identificaciones hayan motivado la legalización de los secuestrados en cuestión, lo que les permitió seguir vivos. Así lo afirma Leda Barreiro ${ }^{8}$, la madre de Mario Alberto Muñoz, otro de los integrantes de este grupo de detenidos fotografiados. La mujer buscaba a su hijo junto con su otro hijo de 9 años. De pronto, cuando caminaban por las calles de la ciudad de Mendoza, el niño

7 Diario Tiempo Argentino, Buenos Aires, 24 de diciembre de 1983

Leda Barreiro de Muñoz es actualmente la presidenta de Abuelas de Plaza de Mayo de la ciudad de Mar del Plata (provincia de Buenos Aires) tiene una hija desaparecida que estaba embarazada al momento de su secuestro. empezó a gritar, es que había visto la foto de su hermano mayor en la tapa del diario El Andino, exhibida en un kiosco establecido por donde circulaba con su madre. Leda Barreiro de Muñoz se dirigió al sitio donde suponía que estaba su hijo -el Departamento de Policía-, con el diario en la mano a modo de prueba.

(...) El tipo que me atendió levantó el teléfono. Nosotros temblábamos Cuando abrió la boca pidió que trajeran a Alberto Muñoz. Alberto apareció marcado por la tortura (...)(GELÓS, 2011, p. 52).

Si analizamos entonces el contexto de producción, imaginamos a un fotógrafo policial tomando las fotografías de esos detenidos por orden de alguna autoridad de esta unidad militar llamada 'centro de instrucción contra subversivo' -según el relato de nuestro entrevistado-. La narrativa del artículo evidencia la intención de generar y alimentar una representación de un "enemigo de la nación: el delincuente subversivo", como se denominaba a todo militante político o sindical opositor. Así dice:

La Policía de la Provincia informó ayer que quedó esclarecido el asesinato por ungrupo de extremistas, del agente Rubén Alberto Cuello (...) los responsables de la muerte de Cuello, que resultaron ser -se informóintegrantes de la organización extremista declarada ilegal en segundo término ${ }^{9}$

Continuamos con el escenario imaginado: en la edición del diario, se coloca la identificación de cada uno de los detenidos, con la autorización, seguramente, del subdirector en ejercicio de la dirección Antonio Di Benedetto que supervisaba todas las notas, según lo declara uno de los periodistas del mismo. Tal vez distintas intencionalidades se entretejieron, una que se evidencia en el hecho de fotografiar a los detenidos en ese estado y se refuerza con el sentido del relato del artículo del diario -construir la representación

9 "Organización extremista declarada ilegal en segundo término" se refería a la organización política militar Montoneros, - peronista de izquierda- que había sido declarada ilegal en segundo término, habiendo sido declarada ilegal en primer término el Ejército Revolucionario del Pueblo la organización política militar del Partido Revolucionario de los Trabajadores -de izquierda trotskista-. 
de un supuesto "enemigo de la nación", otra quizás -no puede afirmarse con certeza- que lleva a los directivos del diario a identificar los rostros de los secuestrados colocando su nombre al pie de cada una de sus fotografías. A su vez las condiciones de enunciación en esa circunstancia histórico-política hacen posible la recepción del relato que los acusa de asesinos del policía.

La representación de "extremistas" identificados como asesinos, malvivientes que difundían las fuerzas armadas era el sustento de enunciación del relato que presentaban las fotografías del diario. Sin embargo, en ese relato se filtraron (?) los epígrafes con la identificación de cada uno de los secuestrados lo que transformaba a la noticia en una prueba de los secuestros y una denuncia de los apresamientos.

Rodolfo Molina, otro de los fotografiados ${ }^{10}$ secuestrados relata lo que le comentó

Pedro Tránsito Lucero, periodista de los diarios referidos apresado también el mismo día del golpe militar. Cuando Molina y Lucero compartían la cárcel, este último le contó que había visto las fotografías de los secuestrados sobre un escritorio de las oficinas de la Policía y se las había llevado a las oficinas donde se editaba el diario. ${ }^{11}$

El subdirector de los diarios El Andino -vespertino-y Los Andes -matutino-, Antonio Di Benedetto fue secuestrado el mismo día del golpe militar, el 24 de marzo de 1976, permaneciendo dos meses secuestrado en calidad de desaparecido y luego dieciocho meses preso hasta que fue obligado a dejar el país ${ }^{12}$. No podemos detallar cómo se articularon estos acontecimientos: fotos con nombres de militantes detenidos desaparecidos hasta ese momento, legalización de los mismos como presos políticos, detención desaparición del subdirector del diario, y seguramente otros tantas cuestiones que componían ese complejo y conflictivo escenario político social, todo ocurrido en el plazo de 30 días - 22 de febrero al 24 de marzo de 1976-.

Sin embargo, la temporalidad de las imágenes, cuya recepción se vincula a su vez con los distintos tiempos de la memoria nos permite hoy una lectura atravesada por otros momentos de la memoria. Los relatos que los

10 Véase foto en el artículo del Diario Los Andes (23.02.76).

11 Entrevista realizada por Lizel Tornay y Fernando Álvarez en San José del Rincón, Santa Fe, en febrero de 2013

12 Antonio Di Benedetto era un escritor argentino destacado y reconocido a nivel internacional a partir de la publicación de su novela Zama (1956). Ernesto Sábato, en mayo de 1976 le había pedido personalmente la libertad del escritor al presidente de la Junta Militar que gobernaba la Argentina, el dictador Jorge Rafael Videla. Varias organizaciones de literatos europeos también habían pedido su libertad. sobrevivientes hacen en el año 2012/13, en condiciones histórico culturales que permiten escucharlos otorgan a esas fotografías el carácter de prueba jurídica, no solo de la existencia de un centro clandestino de detención en el D2 de Mendoza sino de las huellas del horror en los rostros de los secuestrados.

Las condiciones de enunciación y recepción en el momento de las entrevistas -2012/13-, casi treinta años después de finalizada la última dictadura militar en Argentina hacen posible resignificar esas fotografías. Las luchas llevadas a cabo por los organismos de derechos humanos en Argentina, y la movilización social desencadenada en consecuencia, impulsaron, primero, la constitución y posterior informe de la Comisión Nacional por la Desaparición de Personas (CONADEP) en 1984. Más adelante se pudo avanzar con la derogación de las leyes de impunidad sancionadas a fines de la década del ' 80 (de "obediencia debida" y "punto final" que quitaban toda responsabilidad a la mayoría de los represores). Y finalmente, la reapertura de los juicios orales y públicos. Paralelamente el surgimiento del Equipo Argentino de Antropología Forense y su labor en pos de evidenciar la identidad de restos hallados en fosas comunes, las búsquedas de Abuelas de Plaza de Mayo con la resolución de 128 casos resueltos ${ }^{13}$. En la década del ' 90 el nacimiento de nuevos organismos de derechos humanos como H.I.J.O.S. (Hijos por la Identidad y la Justicia contra el Olvido y el Silencio), cambios en las sensibilidades que hicieron posible restituir a quienes fueron víctimas del terrorismo de estado su carácter de sujetos políticos. Y en el momento de estas entrevistas -2012/13- estaban testimoniando y siendo escuchados como tales en el marco de los Juicios orales y públicos, dando cuenta de las prácticas del Estado terrorista de aquellos años.

Innumerables escritos, películas, obras de teatro, programas de televisión, programas escolares, han sido escuchados y aceptados por amplios sectores de la sociedad argentina y por lo tanto esos amplios sectores interpelan los relatos como los que difundía el artículo del diario en cuestión.

Cantidad de casos resueltos-niños/as apropiados/as y recuperados/as, asesinados/as, y embarazos que no llegaron a término- a la fecha de escritura de este artículo (marzo de 2019). 
Todos estas trasformaciones en el escenario político -cambios en las "memorias de la política"14 y en las "políticas de la memoria"15, nuevos actores sociales y políticos, posibilidades nuevas de elaboración de las experiencias traumáticas-, amplían y enriquecen la memoria del pasado reciente.

A partir de diciembre de 2015 el nuevo gobierno nacional ha interpelado en forma directa las "políticas de la memoria" implementadas hasta entonces y ha habilitado el cuestionamiento a las "memorias de la política" que se habían ido construyendo. Nuevos agrupamientos han surgido en el marco de nuevas tensiones. Durante la enorme movilización que se produjo en diversas ciudades del territorio argentino como consecuencia del intento de la Corte Suprema de Justicia de aprobar el " 2 x 1" como modalidad para reducir las condenas de los represores juzgados por delitos de lesa humanidad se presentó públicamente el nucleamiento "Historias desobedientes". Se trata de un colectivo constituido en 2017 por "hijas, hijos y parientes de genocidas" -así se denominan-. Se amplía y complejiza el juego de tensiones en este nuevo "momento de la memoria".

En relación al trabajo que nos convoca, los rasgos que en el contexto de enunciación de febrero de 1976 buscaban construir una representación de los entonces "extremistas" como portadores de alta peligrosidad, hoy pueden ser analizados como las huellas que la política del terror había dejado en sus rostros, hinchados por los golpes, la tortura, y en el caso de nuestra entrevistada por las reiteradas violaciones a la que era sometida diariamente. Nuevas sensibilidades, cuarenta años después entretejidas con múltiples nuevos factores pueden interpelar aquella asociación que buscaba construir el artículo indicando las marcas de esos rostros como consecuencia del "malvivir" de los fotografiados.

14 María Sondereguer (2008) toma por "memorias de la política" la definición de Nora Rabotnikof: "las formas y las narraciones a través de las cuales los que fueron contemporáneos de un período construyen el recuerdo de ese pasado político, narran sus experiencias y articulan, de manera polémica, pasado, presente y futuro", y por "políticas de la memoria", también de NR, "las formas de gestionar o lidiar con ese pasado, a través de medidas de justicia retroactiva,...y su relación con las "grandes ofertas de sentido" o narrativas más generales". (p.5)

\section{A modo de cierre}

El subdirector de los diarios Los Andes y El Andino, Antonio Di Benedetto y varios de los periodistas que trabajaban con él como Alberto Atienza, Rafael Morán, Pedro Tránsito Lucero fueron secuestrados el primer día del golpe militar, el 24 de marzo de 1976, y luego legalizados como presos políticos. Tal vez resulta pertinente preguntarse si las decisiones que probablemente tomaron algunos periodistas y el subdirector de los diarios en cuestión, producidas en el marco de una tarea profesional, podrían considerarse como: “(...) formas afirmativas de resistencia" (HUYSSEN, 2006, p. 380). Dicha pertinencia se relaciona en este punto con la intención de tomar en cuenta las precauciones adecuadas respecto de la "entrada de las víctimas" en la historia del siglo XX evitando la posibilidad de que, como se planteaba al inicio del artículo: “(...) el recuerdo de las víctimas no pudiera coexistir con el de sus combates, sus conquistas, sus derrotas" (TRAVERSO, 2012, p. 296).

\section{BIBLIOGRAFIA}

AMADO, Ana; NORA, Domínguez (comps.). Lazos de familia. Herencias, cuerpos, ficciones, Buenos Aires: Paidós, 2004. https://doi.org/10.5195/reviberoamer.2006.116

BARTHES, Roland. La cámara lúcida. Barcelona: Paidós, 1982.

BLEJMAR, Jordana; FORTUNA, Natalia; GARCÍA, Luis. Instantáneas. Fotografía y dictadura en Argentina América Latina. Buenos Aires: Libraria, 2013.

BRODSKY, Marcelo (comp.). Memoria en Construcción. El debate sobre la ESMA. Buenos Aires: La Marca Editora, 2005. https://doi.org/10.19130/iifl.ap.2006.2.218

CATAROSSI, Arana; Nelly. Casi memorias. Mendoza: Editorial Cultura de Mendoza, 1991.

CRENZEL, Emilio (comp.). Los desaparecidos en la Argentina. Memorias, representaciones e ideas (1983-2008). Buenos Aires: Biblos, 2010.

DIDÍ-HUBERMAN, Georges. Remontajes del tiempo padecido. El ojo de la historia 2. Buenos Aires: Biblos, 2015. https://doi.org/10.23854/autoc.voi2.21 
DUBOIS, Philippe. El acto fotográfico y otros ensayos. Buenos Aires: La Marca Editora, 2015.

FELD, Claudia; SUITES MOR, Jessica (comps.). El pasado que miramos. Memoria e imagen ante la historia reciente. Buenos Aires: Paidós, 2009. https://doi.org/10.5354/0716-3991.2009.15019

GARCÍA, Luis Ignacio. "Imágenes de ningún lugar. Sobre la representación del horror en Argentina”. En: Nombres. Revista de Filosofía,nํ23,añoxix, 2012.

GARCÍA, Luis; LONGONI, Ana. Imágenes invisibles. Acerca de las fotos de los desaparecidos. In: BLEJMAR, Jordana; FORTUNA, Natalia; GARCÍA, Luis. Instantáneas. Fotografía y dictadura en Argentina América Latina. Buenos Aires: Libraria, 2013.

GELÓS, Natalia. Antonio Di Benedetto, periodista. Buenos Aires: Capital Intelectual, 2011.

HUYSSEN, Andreas. "Medios y memoria” (Prólogo). In: FELD, Claudia; STITES MOR, Jessica (comps.). El pasado que miramos. Memoria e imagen ante la historia reciente. Buenos Aires: Paidós, 2009. https://doi.org/10.5354/0716-3991.2009.15019

JELIN, Elizabeth. Los trabajos de la memoria. Madrid: Siglo XXI Editores, 2002.

"LOS DERECHOS HUMANOS y la memoria de la violencia política y la represión: la construcción de un campo nuevo en las ciencias sociales", en Estudios Sociales n. 27, año XIV, $2^{\circ}$ semestre, 2004. https://doi.org/10.14409/es.v27i1.2538

JELIN, Elizabeth. "Revisitando el campo de las memorias" (prólogo). In: Los trabajos de la Memoria. Lima/Perú: Instituto de Estudios Peruanos, 2012.

KAUFMAN, Susana. "Sobre violencia social, trauma y memoria", trabajo presentado en el Seminario: Memoria Colectiva y Represión, Montevideo, 1998.

LA CAPRA, Dominick. Escribir la historia, escribir el trauma. Buenos aires: Nueva Visión, 2005.

MARIN, Louise. Des pouvoirs de l'image: gloses. París: Seuil, 1993

POLLAK, Michael. Memoria, olvido, silencio. La producción social de identidades frente a situaciones límites. La Plata (Buenos Aires): Ediciones al Margen, 2006.

SONDEREGUER, María; CORREA, Violeta (comps.). Análisis de la relación entre violencia sexual, tortura y violación, Cuaderno de Trabajo, UN Quilmes, diciembre, 2008.

TRAVERSO, Enzo. La Historia como campo de Batalla. Interpretar las violencias del siglo XX. Buenos Aires: Fondo de Cultura Económica de Argentina, 2012. https://doi.org/10.18234/ secuencia.voio.1644 